\title{
A Broadband Single-Feed Circularly Polarized Patch Antenna with Wide Beamwidth
}

\author{
Changhong Zhang, Junping Geng, Bin Zhou, Xianling Liang, and Ronghong Jin \\ Department of Electronic Engineering, Shanghai Jiao Tong University, No. 800 Dongchuan Road, Shanghai 200240, China
}

Correspondence should be addressed to Changhong Zhang; changhong@sjtu.edu.cn

Received 24 January 2015; Accepted 24 March 2015

Academic Editor: Giuseppe Mazzarella

Copyright (C) 2015 Changhong Zhang et al. This is an open access article distributed under the Creative Commons Attribution License, which permits unrestricted use, distribution, and reproduction in any medium, provided the original work is properly cited.

\begin{abstract}
A broadband single-feed circularly polarized patch antenna with wide beamwidth is presented. The patch is coupled to four asymmetric cross slots via a microstrip ring with eight matching segments underneath the ground plane, traversing through the arms of the cross slots in a serial manner. And a coupling slice instead of a resistive load is used as matching load of the microstrip ring for higher gain. Furthermore, a metal side wall surrounding the antenna is used to improve the isolation between adjacent elements in an array. Through optimizing the four asymmetric cross slots and eight matching segments, excellent performances are achieved by the proposed antenna, especially for the broadband and wide beamwidth. Measurement results show that the antenna has $-10 \mathrm{~dB}$ reflection coefficient bandwidth of $29.7 \%, 3-\mathrm{dB}$ axial-ratio bandwidth of $21.6 \%$, and beamwidth of more than $90^{\circ}$. It can be considered as a good candidate for the element of arrays.
\end{abstract}

\section{Introduction}

With the rapid development of modern wireless communication systems, circularly polarized $(\mathrm{CP})$ patch antennas using single-feed have received considerable attention due to the reduction of RF loss and complexity in an array feed. And high qualities are also desired in single-feed CP patch antennas, such as broadband for the high-capacity and highspeed data-rate communication, wide beamwidth to improve the coverage area in base station and GPS applications, and so on.

In recent years, many designs of the $\mathrm{CP}$ patch antennas with improvements on the broadband and wide beamwidth have been reported. A novel leaky-wave slot antenna exhibited $10 \mathrm{~dB}$ return loss bandwidth of $40 \%, 3-\mathrm{dB}$ AR bandwidth of $53 \%$, but with a tilt-beam [1]. In [2], a horizontally meandered strip feed technique was proposed to achieve an impedance bandwidth of about $25.8 \%$ and a $3-\mathrm{dB}$ AR bandwidth and beamwidth of about $13.5 \%$ and $64^{\circ}$, respectively, at the expense of four layers. A CP patch antenna with a pyramidal ground structure and a partially enclosed flat conducting wall obtained a 3-dB axial-ratio beamwidth of more than $130^{\circ}$, but the bandwidth is narrow [3]. Slot coupled
$\mathrm{CP}$ antennas have been intensively studied because of their advantages of wide bandwidth and feeding flexibility [4-9]. By adopting the concept of nonuniformity on the coupling slots and microstrip ring, a broadband dual circularly polarized patch antenna realized 10- $\mathrm{dB}$ return loss bandwidth of $24 \%$, 3-dB axial-ratio bandwidth of $16 \%$, and beamwidth of $110^{\circ}$, which possessed both the advantages of broadband and wide beamwidth [10].

In this paper, a broadband single-feed $\mathrm{CP}$ patch antenna with wide beamwidth is presented. Based on the dual circularly polarized antenna introduced in [10], the proposed antenna has three improvements. Firstly, the parameters of the coupling slots and microstrip ring have more than two degrees of freedom; wider bandwidth is obtained by optimization. Secondly, through a coupling slice, the remainder of the energy at the end of the microstrip ring can be coupled to the patch rather than being absorbed by a resister load; thus higher gain is achieved. Finally, a metal side wall surrounding the antenna is used to suppress the coupling between adjacent elements in an array for higher isolation. The remainder of this paper is organized as follows. Section 2 explains the basic design of the proposed antenna. In Section 3, a prototype of the antenna is fabricated and the performances are verified 
based on the experiment. Finally, the conclusion is given in Section 4.

\section{Antenna Configuration and Design Concept}

Figure 1 shows the configuration of the proposed antenna, which consists of two substrates, one side wall, and one cavity, from up to down, substrate 1 , substrate 2 , side wall, and cavity. A radiation patch with the radius of $R_{1}$ locates at the bottom of substrate 1 , and a parasitic patch with the radius of $R_{2}$ locates at the upside of substrate 1 . A metal ground plane is on the top surface of substrate 2, and a microstrip ring feed network is on the bottom of substrate 2. The radiation patch is separated from the ground plane with a height of $h_{a}$ to construct an air substrate for wideband. The ground plane is carved with four asymmetric cross slots for coupling, which have eight arms with different lengths and widths. Underneath the ground plane, the microstrip ring with a radius of $R$ travels through the arms of cross slots and couples the electromagnetic energy to the cross slots in a serial manner. The microstrip ring contains eight matching segments with different widths corresponding to the eight arms of the cross slots and ends up with a coupling slice with radius of $r_{2}$ serving as a matching load. Besides, an additional matching segment is used to obtain $50 \Omega$ matching with the SMA port. Furthermore, a metal side wall surrounding the antenna is used to suppress the coupling between adjacent elements in an array. Finally, a metal cavity with the same radius of $R_{1}$ as the radiation patch and height of $h_{c}$ is added to reduce the back radiation of coupling slots and improve the directivity. Both substrates with permittivity of 2.55 , loss tangent of 0.0018 , and thickness of $0.762 \mathrm{~mm}$ are chosen. The dimension of the antenna is $W_{g} \times$ $W_{g}$.

The transmission line model of the antenna is illustrated in Figure 2. The couplings between the feed and slot and between the slot and patch are modelled by the two transformers with the turn ratios " $n_{f i}$ " and " $n_{p i}$ " detailed explanation of which can be found in [11, 12]. In this design, $\varphi_{1}$ is equal to $90^{\circ}$ and $\varphi_{2}$ is equal to $45^{\circ}$ at the centre frequency for quarter-wave transformer and circular polarization, respectively.

For circular polarization, two orthogonal modes with $90^{\circ}$ phase difference are generated by the eight coupling points with $45^{\circ}$ difference in phase and space in a serial manner. And the amplitude of the two orthogonal modes can reach the same level by adjusting $n_{p i}(i=1-8)$, which are related to the lengths and widths of the coupling slots. Therefore the pure circular polarization can be obtained by optimization with the eight degrees of freedom. Furthermore, each coupling point serves as second source, based on which the antenna has eight equivalent feeding points with $45^{\circ}$ difference in phase and space in a serial manner, thus wide axial-ratio beamwidth is achieved by multifeeding scheme because it can suppress the higher modes and cross polarized components of such microstrip antenna with thick substrate [13]. Refer to Figure 1; the right-hand circular polarization (RHCP) will be generated.
For broadband impedance bandwidth, eight matching segments are adopted in the microstrip ring. The value of $n_{f i}$ relevant to $Z_{s i}$ and the impedance transformation between adjacent segments are both controlled by the width $W_{c i}$. The feed line can be well matched in broadband by optimizing the values of $W_{c i}(i=1-8)$. Figure 3 shows the current distribution on the microstrip ring and the ground plane in time domain. It can be seen clearly that the feed line generates a quasi travelling wave, which proves that the microstrip ring is wellmatched in a serial manner. Moreover, patch 1 serves as a radiation patch and patch 2 serves as a parasitic patch. They have two resonance frequencies close to each other, which also contributes to improve the impedance bandwidth.

For higher gain, a coupling slice is applied to the antenna serving as a matching load at the end of the microstrip ring, where a resistive load is usually placed. Through a coupling slice, the remainder of the energy at the end of the microstrip ring can be coupled to the patch rather than absorbed by a resister; thus higher gain is achieved. Figure 4 shows the simulated gains and reflection coefficient of the antenna with coupling slice and resistive load, respectively. And the current distribution of coupling slice is also demonstrated in Figure 4, which proves that the remainder of the energy at the end of the microstrip ring can be coupled to the patch by using a coupling slice. Around the centre frequency of $3.7 \mathrm{GHz}$, the difference between the coupling slice and resistive load is very little. Because of the fact that the antenna is optimized for the best performances at the centre frequency, the remainder of the feeding energy at the end of the microstrip ring is almost negligible. Away from the centre frequency, the remainder of the feeding energy increases. The difference between the gain of the antenna with coupling slice compared to the one with resister load is about $0.2 \mathrm{dBic}$ at the higher band from $3.8 \mathrm{GHz}$ to $4.1 \mathrm{GHz}$ and $0.2 \mathrm{dBic}$ to $1.3 \mathrm{dBic}$ at the lower band from $3.5 \mathrm{GHz}$ to $3 \mathrm{GHz}$. The coupling slice has obvious advantage when the remainder of the feeding energy rises. At the other hand, the reflection coefficient of the antenna with coupling slice is as good as the one with resister load during the band, which proves that the coupling slice is a good substitute of a resister load for higher gain.

For higher isolation between adjacent elements in an array, a metal side wall surrounding the antenna is used. With regard to small antenna arrays, the coupling between adjacent elements is mainly caused by surface wave propagation and near field radiation. In this paper, the array with only two elements is considered. Figure 5 shows the array layout and current distribution on the ground plane of the antenna array with and without side wall, which illustrates that the side wall can prevent the current transmit from one element to another directly. This phenomenon indirectly proves that the sidewall can suppress the surface wave propagation between adjacent elements in an array. And the simulated near field of the antenna with and without side wall at the three frequencies of $3 \mathrm{GHz}, 3.7 \mathrm{GHz}$, and $4.2 \mathrm{GHz}$ is displayed in Figure 6. It demonstrates that the side wall has some influence on the near field radiation, which will increase the near field coupling. Thus the side wall has the influence of two aspects on the isolation. One is suppressing the surface wave propagation for higher isolation, and the other is increasing 


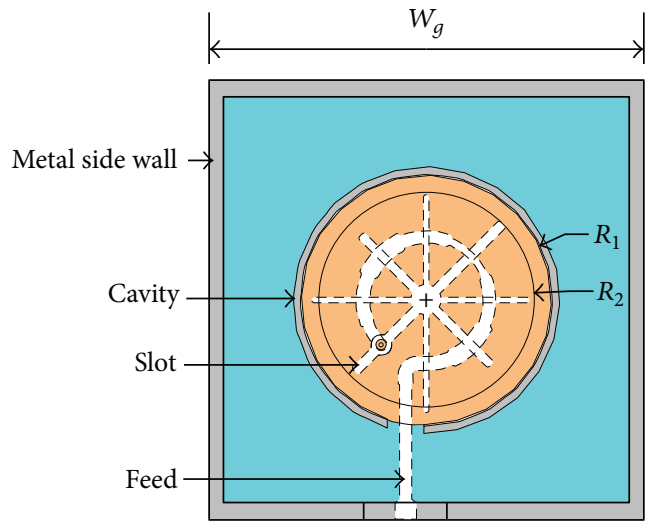

(a)

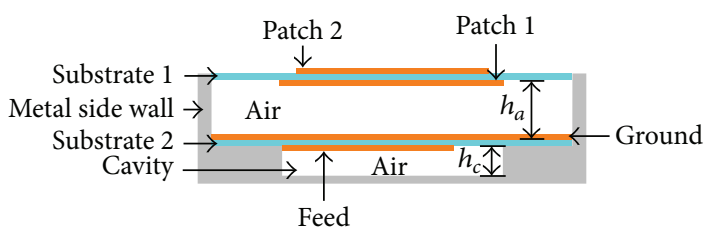

(b)

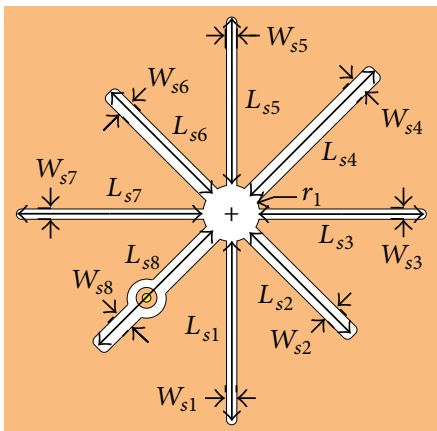

(c)

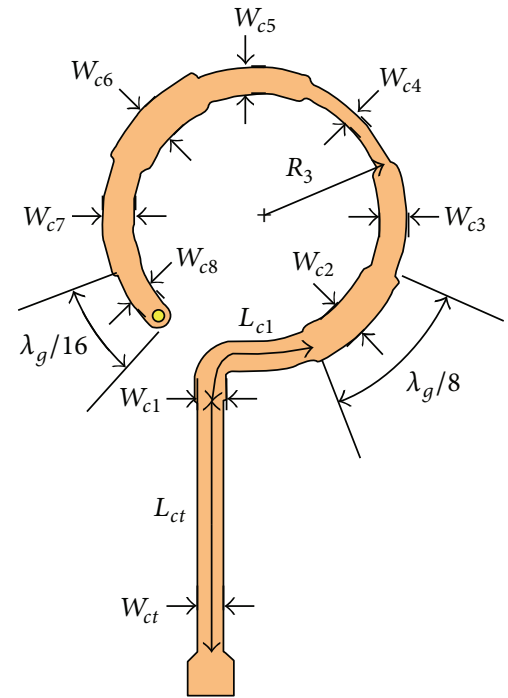

(d)

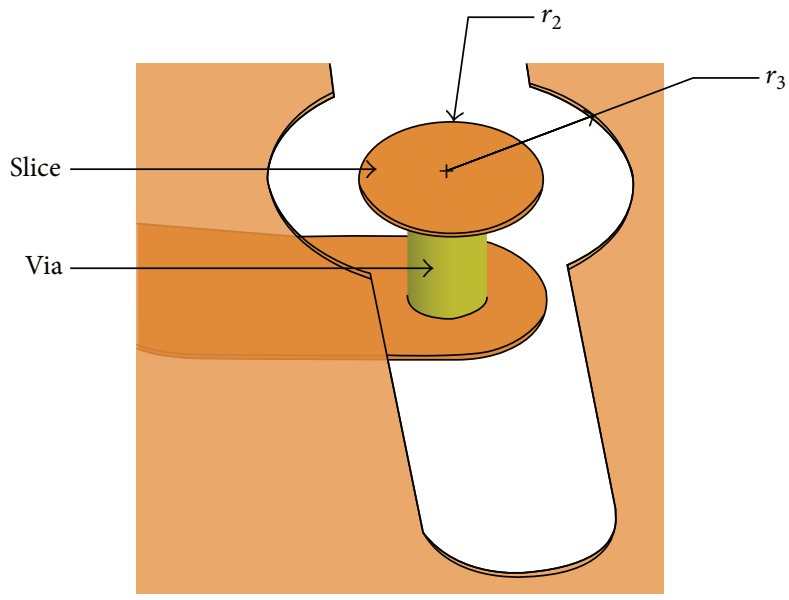

(e)

Figure 1: The configuration of the proposed antenna. (a) The front view. (b) The side view. (c) Coupling slots. (d) Microstrip ring. (e) Coupling slice. 


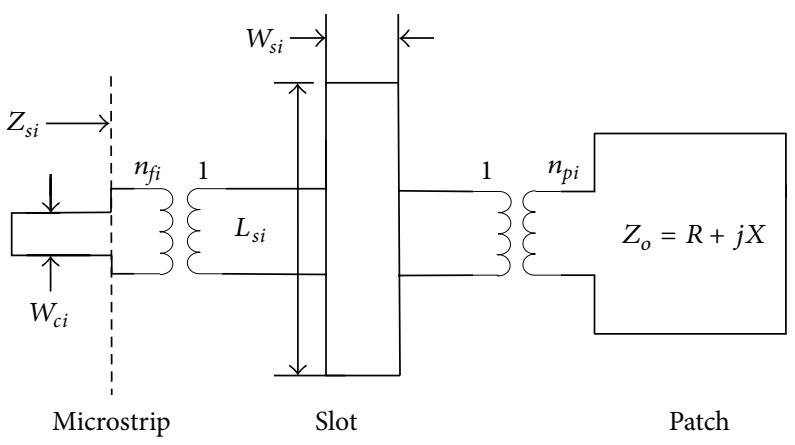

(a)

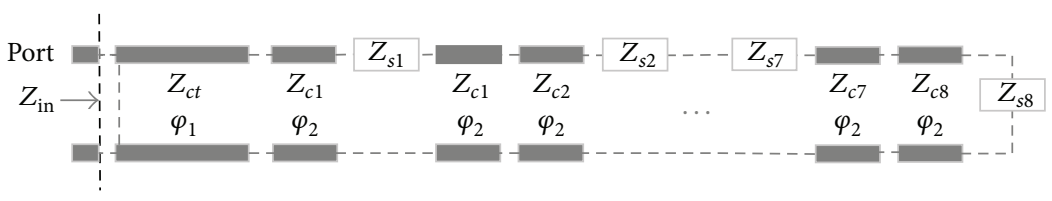

(b)

Figure 2: Transmission line model of the antenna. (a) Transmission line model of the slot coupling $\left(Z_{s i}(i=1-8)\right.$ express the equivalent impedance of the slot coupling; $Z_{o}$ expresses the equivalent impedance of the radiation patch). (b) Transmission line model of the microstrip ring $\left(Z_{\text {in }}\right.$ expresses the input impedance of the port; $Z_{c t}$ expresses the characteristic impedance of the transformation line for matching with $50 \Omega ; Z_{c i}(i=1-8)$ express the characteristic impedance of the matching segments; $\varphi_{i}(i=1,2)$ are the phase delay of each matching segment).

the near field coupling and reducing the isolation. Figure 7 depicts the simulated isolation of the adjacent elements with and without side wall in an array. At the centre frequency, the antenna with and without side wall has the highest near field over the band. And the near field of the antenna with side wall has a maximum value of $66.3 \mathrm{~dB}$, about $6 \mathrm{~dB}$ higher than the one without side wall. The isolation with side wall has a reduction of $3 \mathrm{~dB}$ compared to the one without side wall. It is due to the fact that the increased near field coupling overtakes the advantage of the side wall. However, the advantages of the side wall become obvious off the centre frequency, especially at the higher band. The near field of the antenna with side wall has a maximum value of $60.6 \mathrm{~dB}$ and $62.5 \mathrm{~dB}$ at the lower and higher band and about $5.4 \mathrm{~dB}$ and $3.4 \mathrm{~dB}$ higher than the one without side wall, respectively. The isolation has an improvement of about $4-\mathrm{dB}$ at the lower band and $10-\mathrm{dB}$ at the higher band. The advantage of the side wall overtakes the increased near field coupling, while more surface waves are generated off centre frequency.

For higher front-to-back ratio, a back cavity is located vertically below the slots. Figure 8 shows the simulated radiation pattern with and without back cavity. The front-toback ratio of the antenna with back cavity is $22 \mathrm{~dB}$ and $10.6 \mathrm{~dB}$ higher than the one without back cavity. The directivity of the antenna with back cavity is $8.46 \mathrm{dBic}$ and $0.16 \mathrm{~dB}$ higher than the one without back cavity. Simulation results show that the back cavity has a great improvement on the front-to-back ratio and a little improvement on the directivity.

\section{Results and Discussions}

According to the practical application, the antenna operated at the centre frequency of $3.7 \mathrm{GHz}$. The optimization of the
TABLE 1: Optimized parameters of the proposed antenna.

\begin{tabular}{lccccccccc}
\hline Parameters & $R_{1}$ & $R_{2}$ & $R_{3}$ & $r_{1}$ & $r_{2}$ & $r_{3}$ & $h_{a}$ & $h_{c}$ & $L_{c 1}$ \\
\hline Values/mm & 15.4 & 13.1 & 7.7 & 2 & 0.6 & 1.9 & 8.1 & 5 & 5.9 \\
\hline Parameters & $L_{c t}$ & $W_{c t}$ & $W_{g}$ & $W_{s 1}$ & $W_{s 2}$ & $W_{s 3}$ & $W_{s 4}$ & $W_{s 5}$ & $W_{s 6}$ \\
\hline Values/mm & 14 & 1.5 & 53 & 0.8 & 1.2 & 0.7 & 1.2 & 1.3 & 1.1 \\
\hline Parameters & $W_{s 7}$ & $W_{s 8}$ & $L_{s 1}$ & $L_{s 2}$ & $L_{s 3}$ & $L_{s 4}$ & $L_{s 5}$ & $L_{s 6}$ & $L_{s 7}$ \\
\hline Values/mm & 0.8 & 1.4 & 13.2 & 10.5 & 12.2 & 12.7 & 12.5 & 10.7 & 13.6 \\
\hline Parameters & $L_{s 8}$ & $W_{c 1}$ & $W_{c 2}$ & $W_{c 3}$ & $W_{c 4}$ & $W_{c 5}$ & $W_{c 6}$ & $W_{c 7}$ & $W_{c 8}$ \\
\hline Values/mm & 11.7 & 1.7 & 2.1 & 1.5 & 0.9 & 1.5 & 2.2 & 1.7 & 1.4 \\
\hline
\end{tabular}

proposed antenna is carried out with CST Microwave Studio software based on the finite integration technique (FIT) method. The optimized parameters of the antenna are listed in Table 1.

Based on the parameters in Table 1, a prototype is fabricated and measured. The simulated and measured results including reflection coefficient, radiation pattern, gain, and axial-ratio are compared.

Figure 9 shows the reflection coefficient of the proposed antenna. The test antenna achieves a measured impedance bandwidth of $29.7 \%$ for reflection coefficient less than $-10 \mathrm{~dB}$, covering the frequency range from $3 \mathrm{GHz}$ to $4.1 \mathrm{GHz}$. The measured and simulated results of reflection coefficient are a little different mainly due to the fabrication error and manual assembly error.

The radiation patterns in the phi $=0^{\circ}$ and $\mathrm{phi}=90^{\circ}$ planes at the centre frequency of $3.7 \mathrm{GHz}$ are depicted in Figure 10. The measured results are well matched with the simulated ones in the main lobe. The radiation patterns have a good symmetry with no tilted beam at the boresight. The 

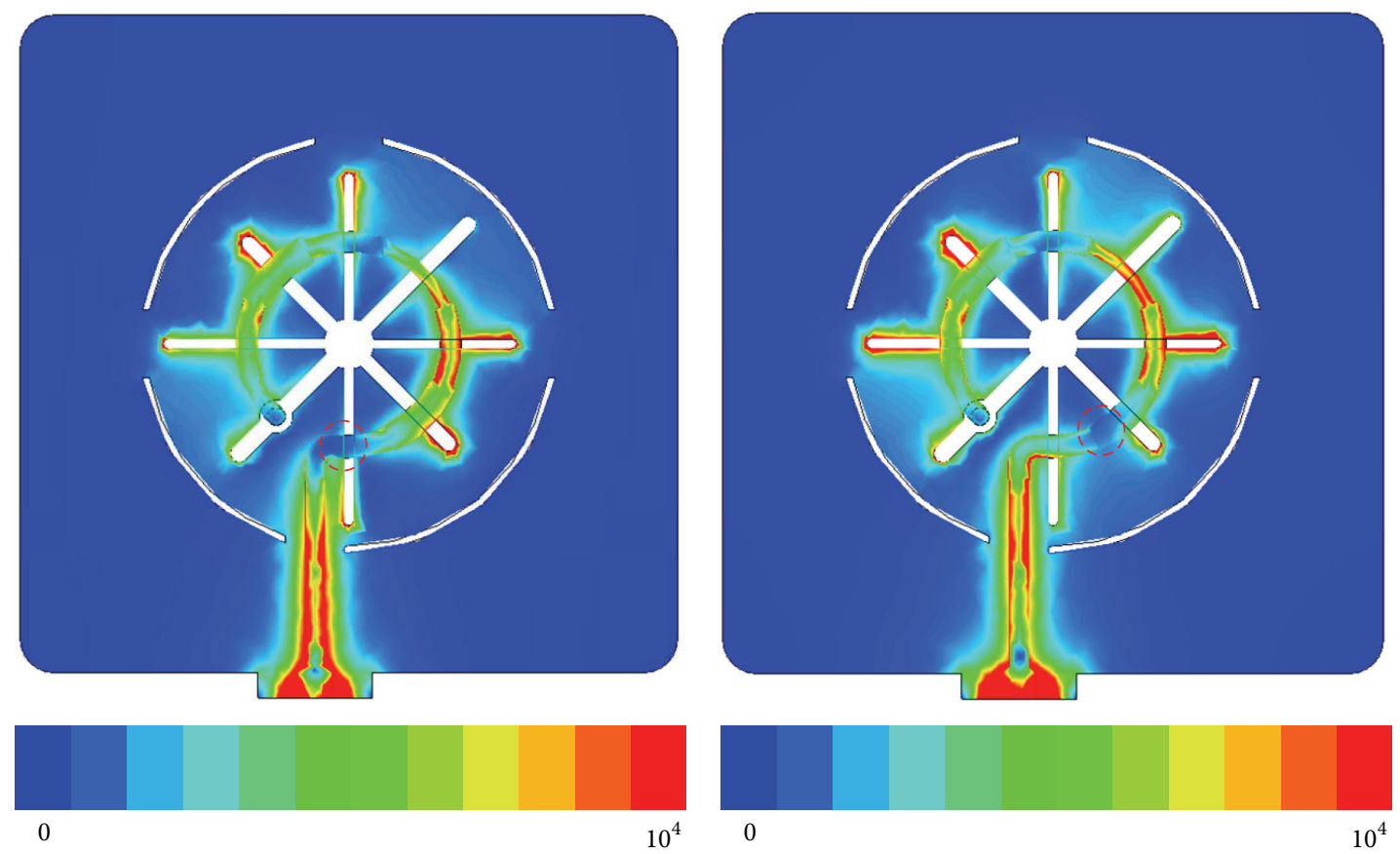

$v(\mathrm{~m})$

(a)

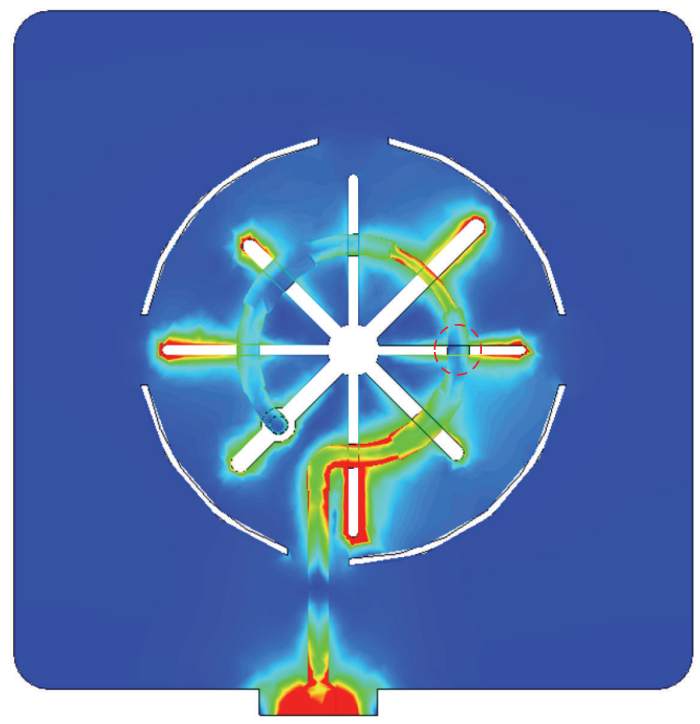

(b)
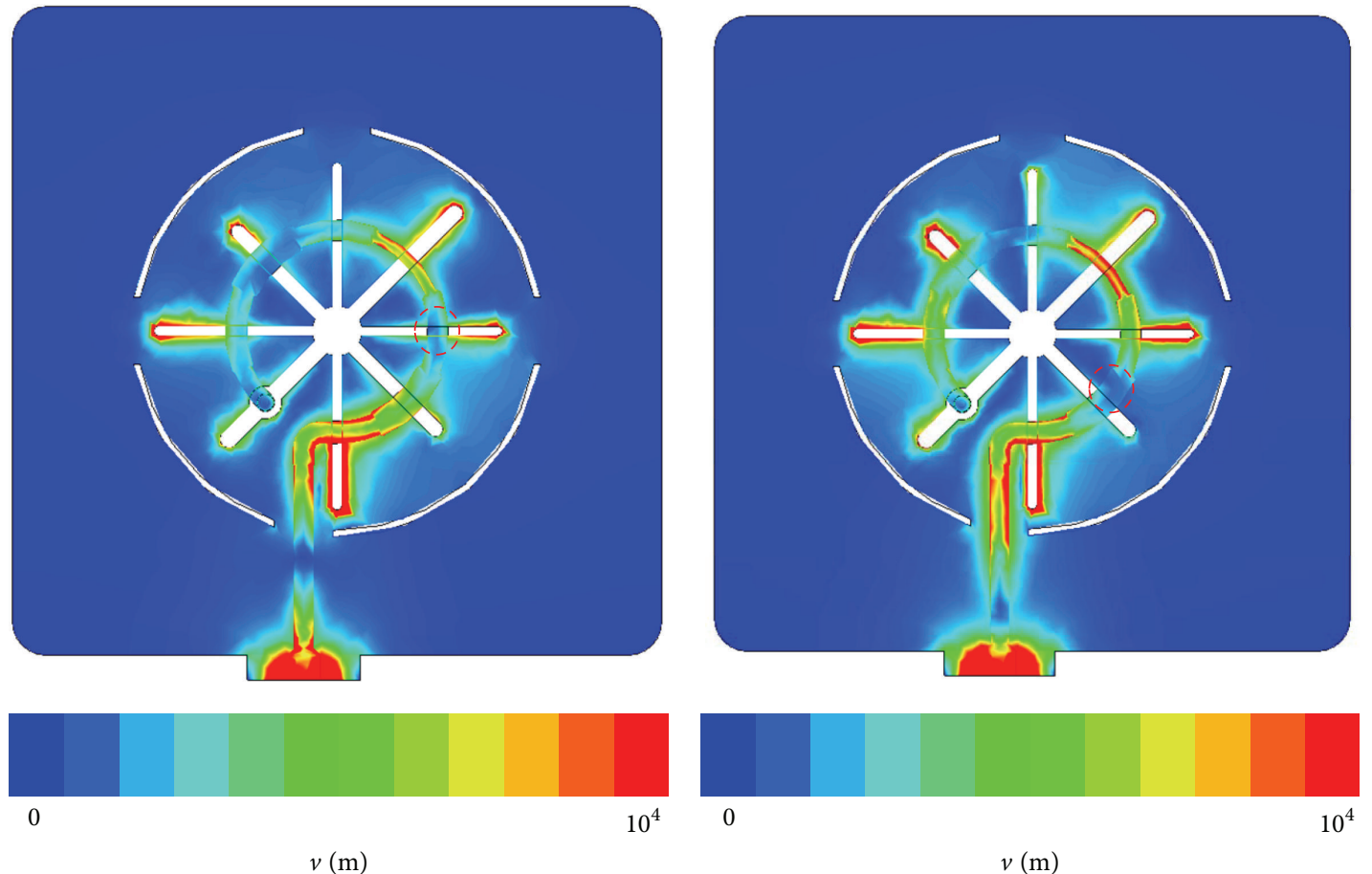

(c)

(d)

Figure 3: Current distribution of the feed line and the ground plane for different values of the phase angle. (a) $0^{\circ}$. (b) $30^{\circ}$. (c) $60^{\circ}$. (d) $90^{\circ}$. (The red circle shows the minimum current on the microstrip ring.)

3- $\mathrm{dB}$ beamwidth is about $70^{\circ}$. The gain at the zenith versus frequency is shown in Figure 11. The measured gain is higher than $7.4 \mathrm{dBic}$ across the band from $3 \mathrm{GHz}$ to $4.2 \mathrm{GHz}$ with the peak gain of $8.6 \mathrm{dBic}$ at $4 \mathrm{GHz}$.
The antenna is tested in an open space. In order to measure the axial-ratio, the tested antenna rotates slowly around the vertical line, and the linearly polarized transmitting antenna spins fast around the horizontal line. The 


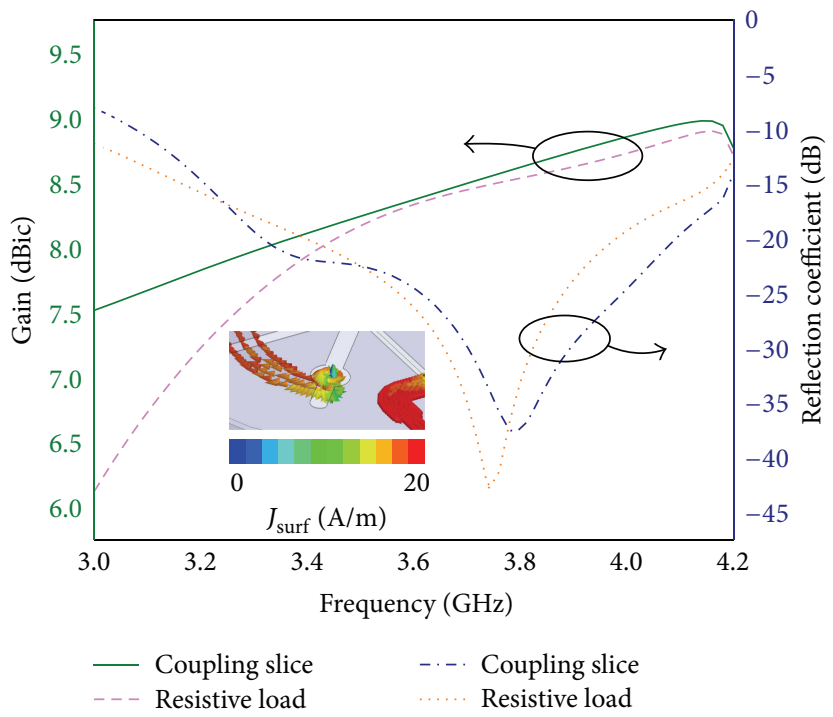

FIgURE 4: Comparisons of the gains and reflection coefficient of the antenna with coupling slice and resistive load, respectively.
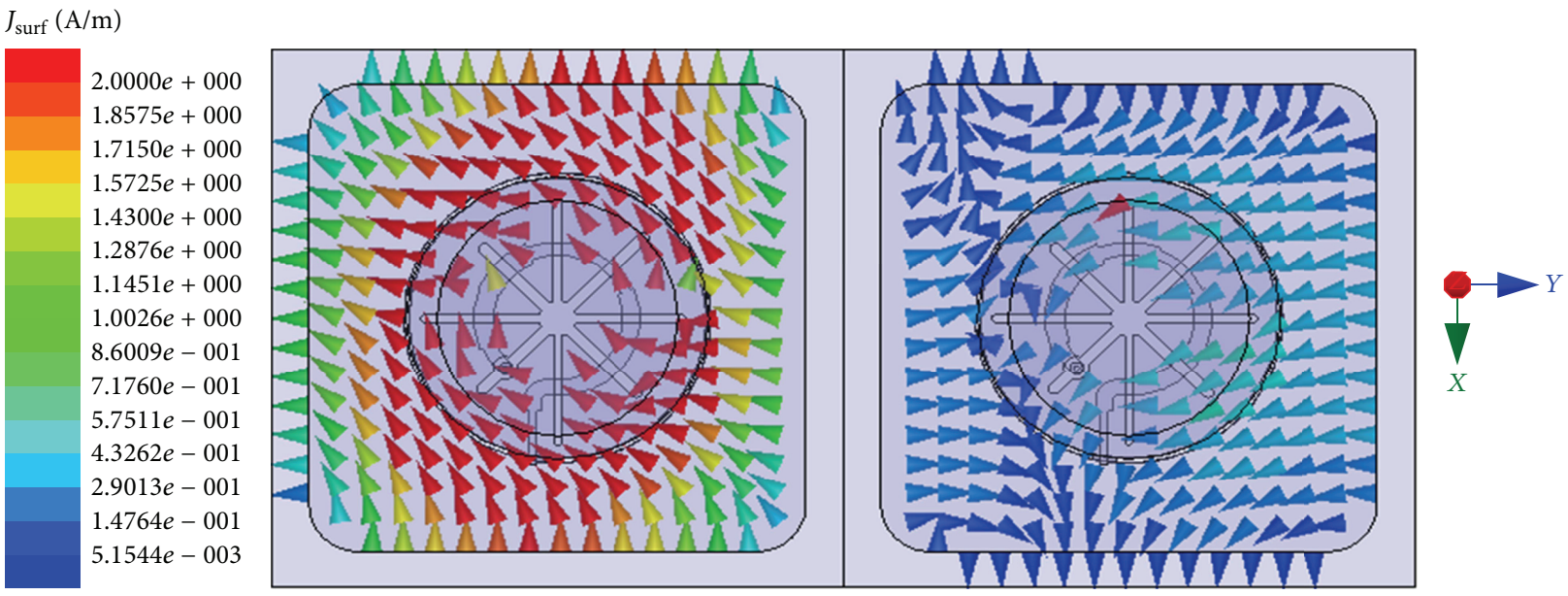

(a)
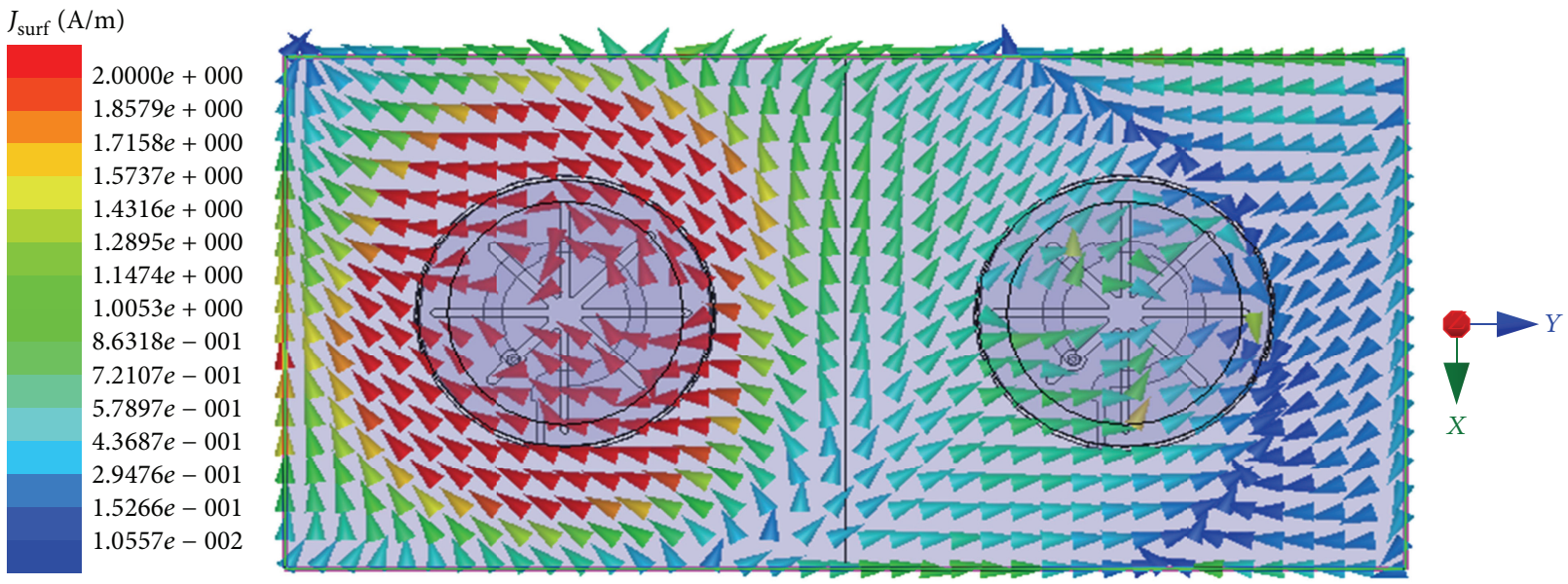

(b)

FIGURE 5: The simulated current distribution on the ground of the antenna array at the centre frequency of $3.7 \mathrm{GHz}$. (a) With side wall. (b) Without side wall. 


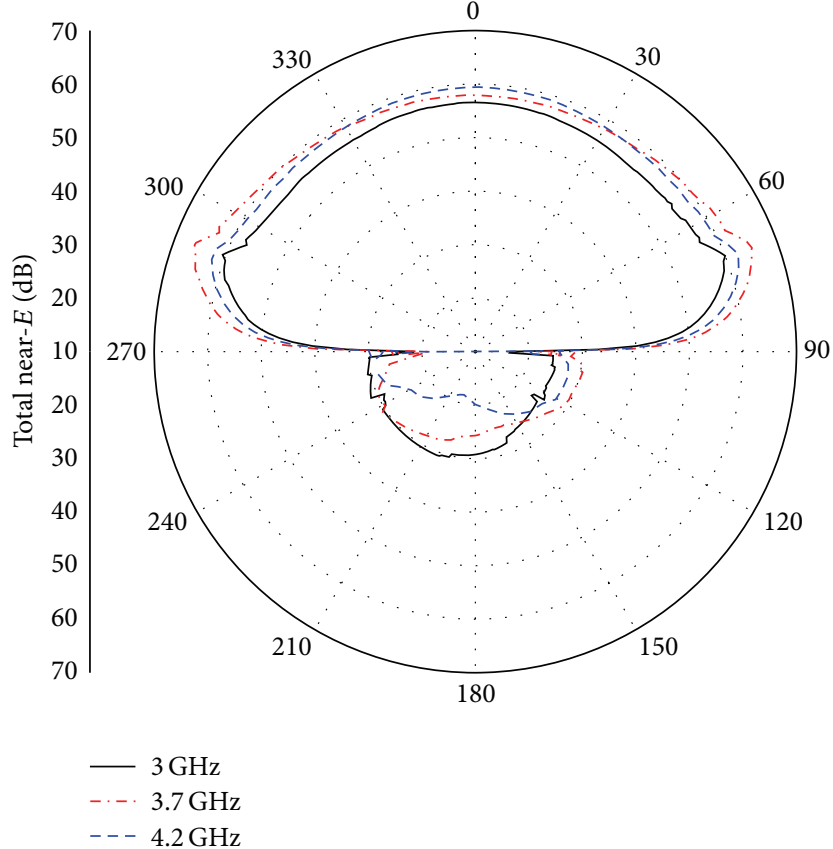

(a)

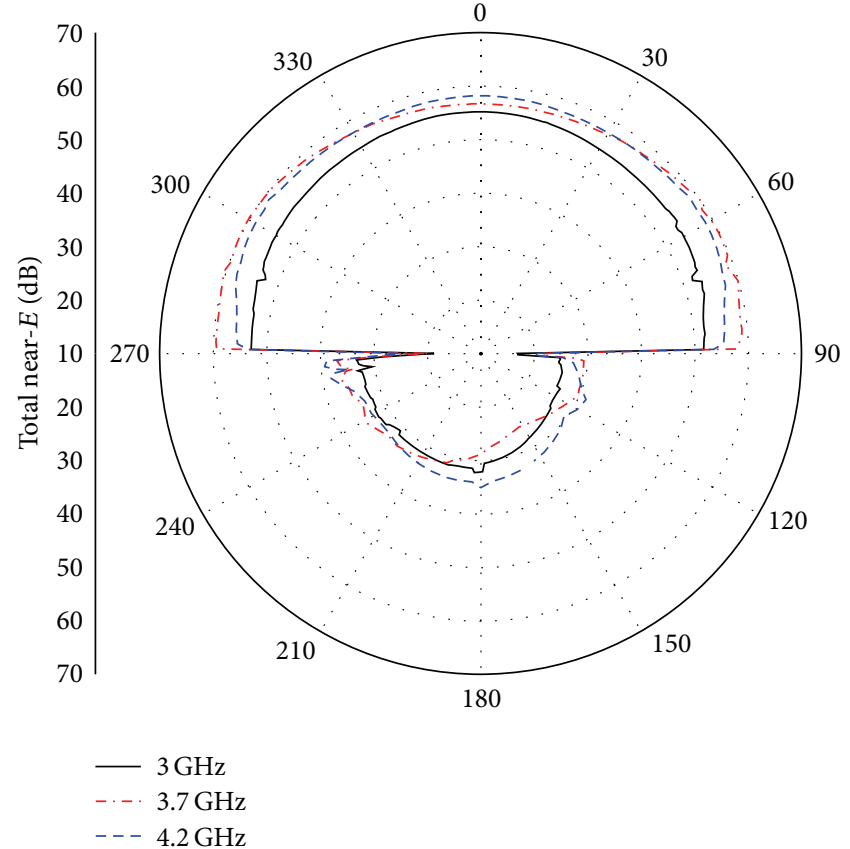

(b)

FIGURE 6: The simulated near field radiation at the three frequencies of $3 \mathrm{GHz}, 3.7 \mathrm{GHz}$, and $4.2 \mathrm{GHz}$. (a) With side wall. (b) Without side wall.

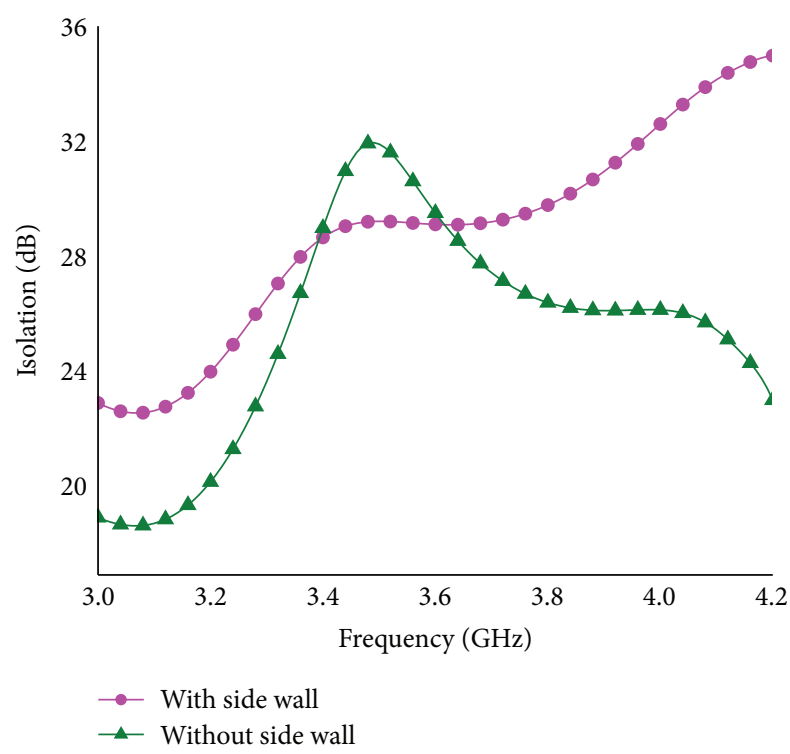

FIgURE 7: The simulated isolation of the adjacent elements with and without side wall in an array.

axial-ratios in the phi $=0^{\circ}$ and phi $=90^{\circ}$ planes at the centre frequency of $3.7 \mathrm{GHz}$ are illustrated in Figure 12. The measured results of axial-ratio are worse than the simulated ones and deviate from the trend line. The deterioration of the axial-ratio is maybe caused by the fabrication and assembly error. The deviation is due to the limited speed of the spinning

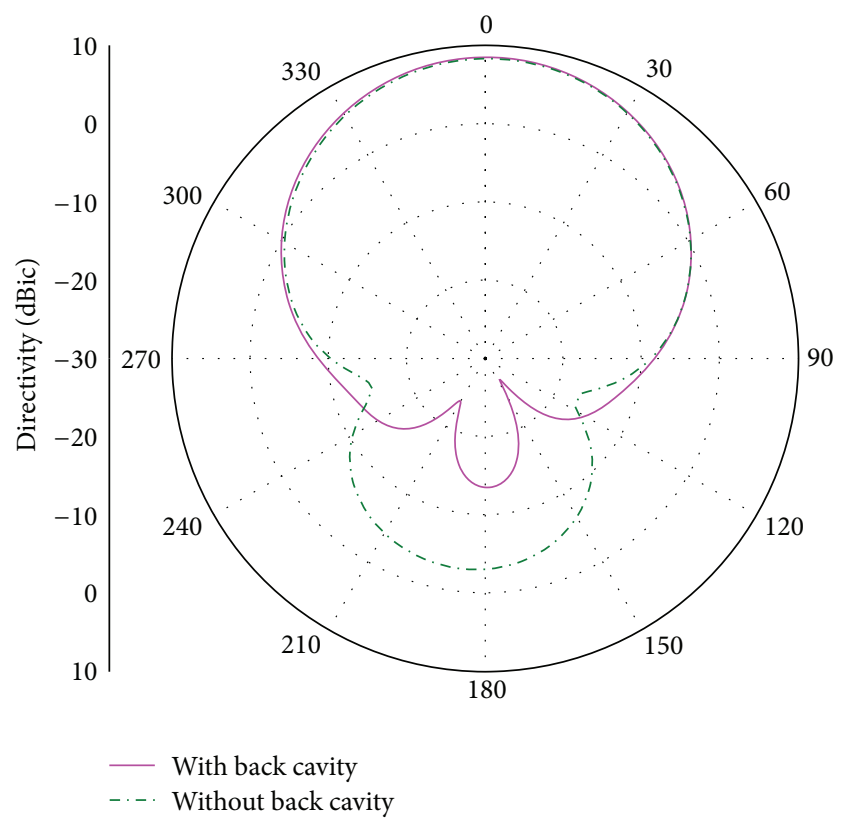

FIGURE 8: The simulated radiation pattern with and without back cavity.

linearly polarized antenna, and the noise in testing environment, where the multipath effect has some influence on the measurement in an open space. The measured axial-ratio has $3-\mathrm{dB}$ beamwidth of $90^{\circ}$ in the plane of phi $=0^{\circ}$ and $100^{\circ}$ in the plane of $\mathrm{phi}=90^{\circ}$. And the axial-ratio at the zenith versus 


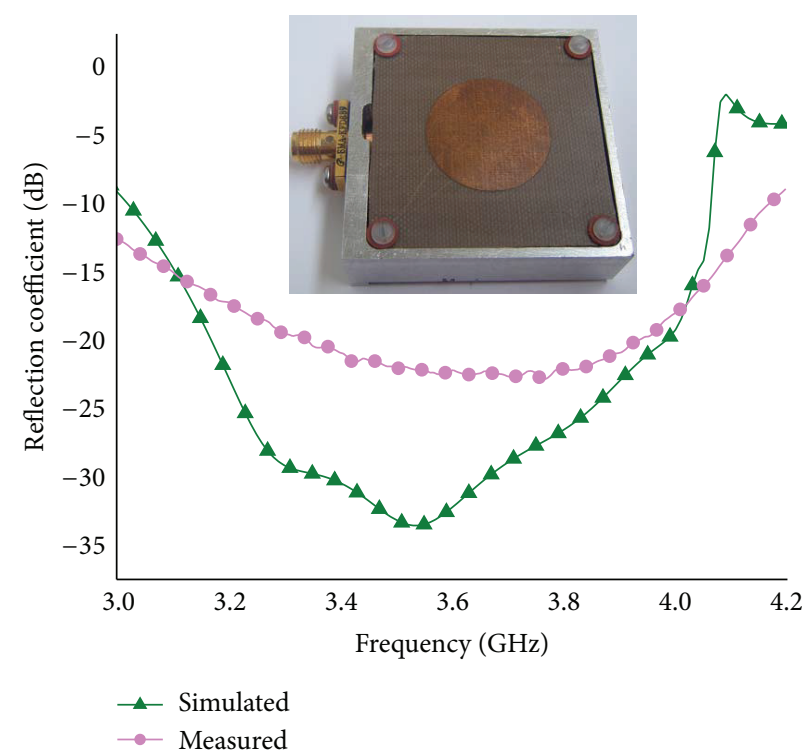

FIGURE 9: Reflection coefficient of the proposed antenna.

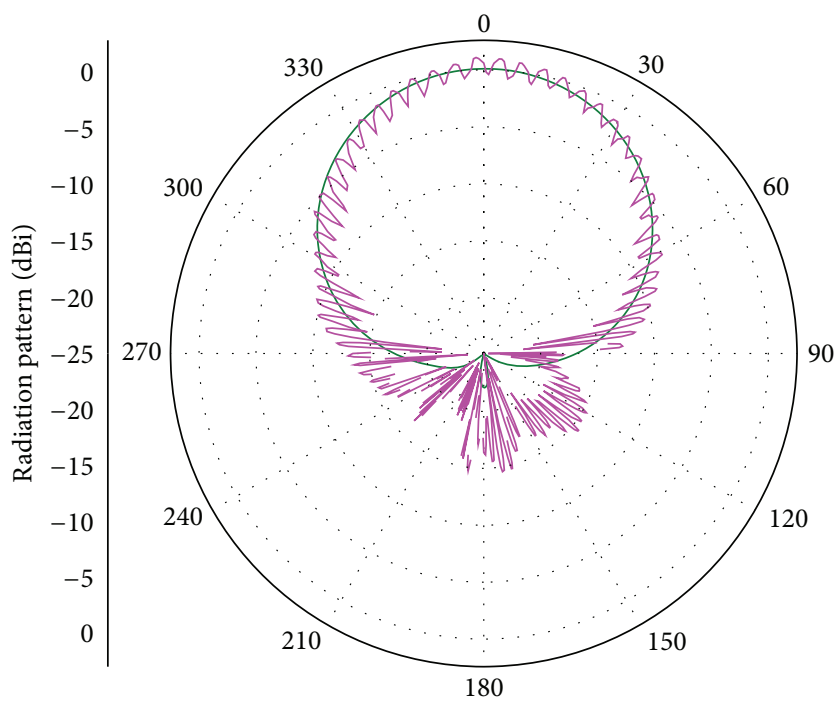

- Simulated

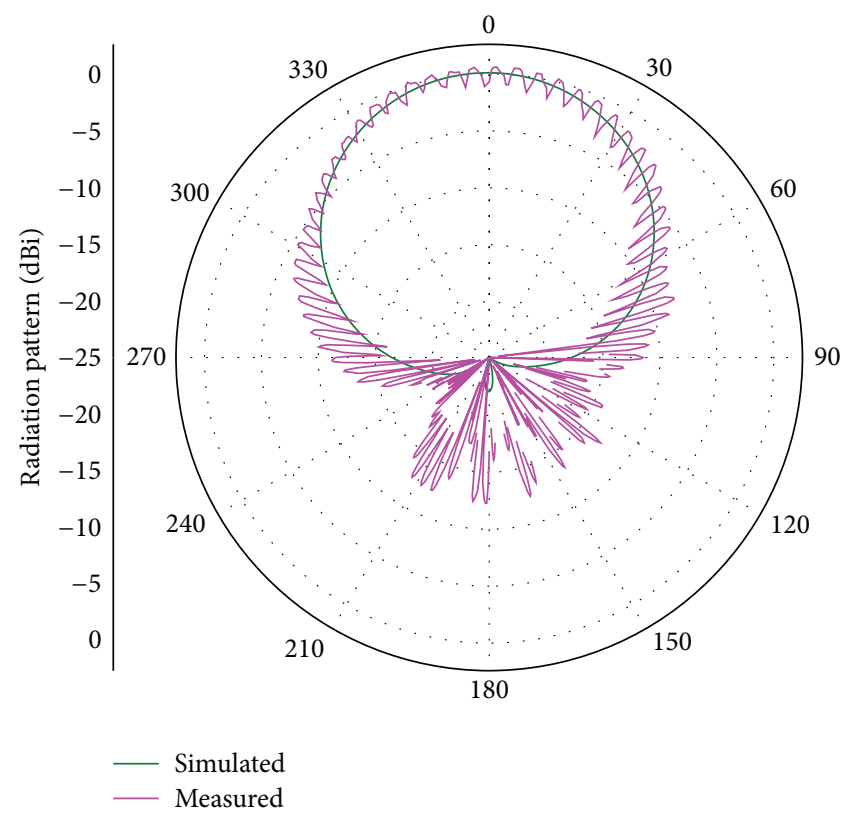

(b)

FIGURE 10: Radiation pattern of the proposed antenna at the centre frequency of $3.7 \mathrm{GHz}$. (a) in the plane of $0^{\circ}$. (b) In the plane of $90^{\circ}$.

frequency is shown in Figure 13. The simulated and measured bandwidths of $3-\mathrm{dB}$ axial-ratio are about $21.6 \%$ from $3.3 \mathrm{GHz}$ to $4.1 \mathrm{GHz}$. The total excellent performances of the proposed antenna are summarized in Table 2.

\section{Conclusion}

A broadband single-feed circularly polarized patch antenna with wide beamwidth is presented in this paper. Eight matching segments are adopted to the microstrip ring for broadband, and four asymmetric cross slots are used to generate pure circular polarization with wide beamwidth. The excellent performances of the antenna are proved by a prototype, which make the antenna very suitable for array design.

\section{Conflict of Interests}

The authors declare that there is no conflict of interests regarding the publication of this paper. 


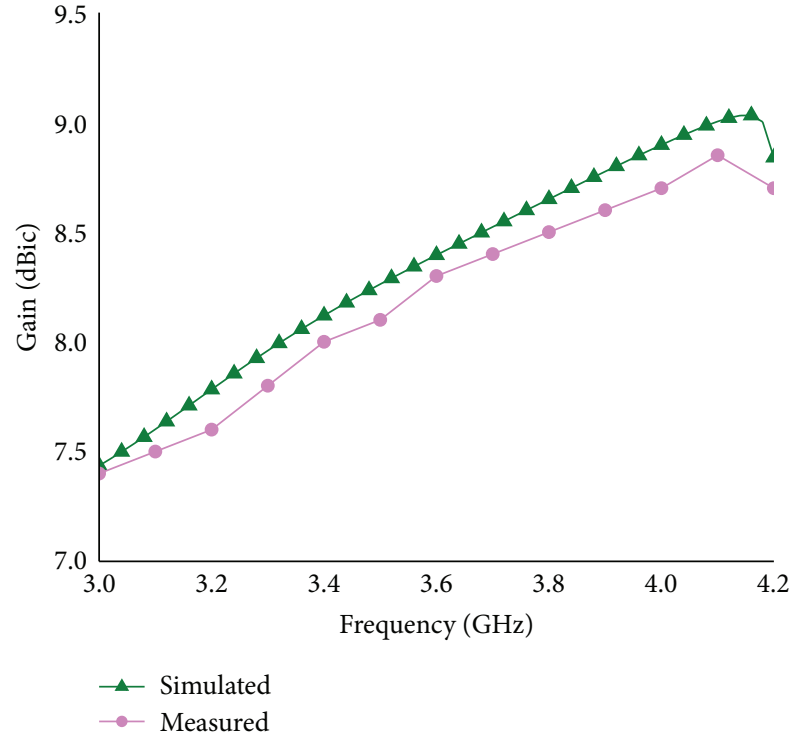

FIGURE 11: Gain of the antenna versus frequency.

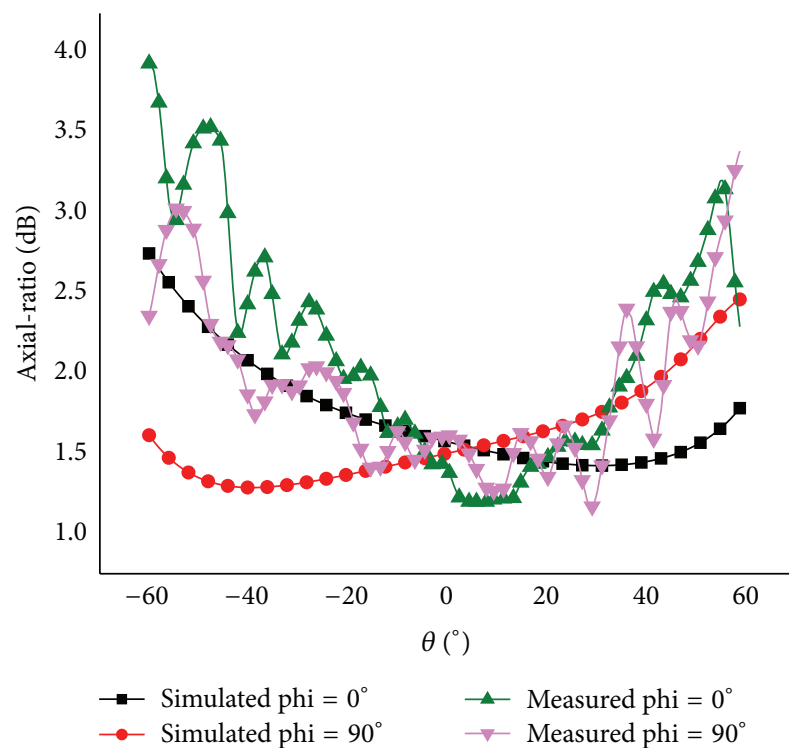

FIgURE 12: Axial-ratio in the plane of phi $=0^{\circ}$ and phi $=90^{\circ}$ at the centre frequency of $3.7 \mathrm{GHz}$.

TABLE 2: Performances of the proposed antenna.

\begin{tabular}{lcc}
\hline Performance & Simulated & Measured \\
\hline -10 dB reflection coefficient bandwidth & $27 \%$ & $29.7 \%$ \\
Peak gain & $8.8 \mathrm{dBic}$ & $8.6 \mathrm{dBic}$ \\
3-dB gain beamwidth & $70^{\circ}$ & $70^{\circ}$ \\
Front-to-back ratio & $>20 \mathrm{~dB}$ & $>13 \mathrm{~dB}$ \\
3-dB axial-ratio beamwidth $\left(\mathrm{phi}=0^{\circ}\right)$ & $>120^{\circ}$ & $90^{\circ}$ \\
3-dB axial-ratio beamwidth $\left(\mathrm{phi}=90^{\circ}\right)$ & $>120^{\circ}$ & $100^{\circ}$ \\
3-dB axial-ratio bandwidth & $21.6 \%$ & $21.6 \%$ \\
\hline
\end{tabular}

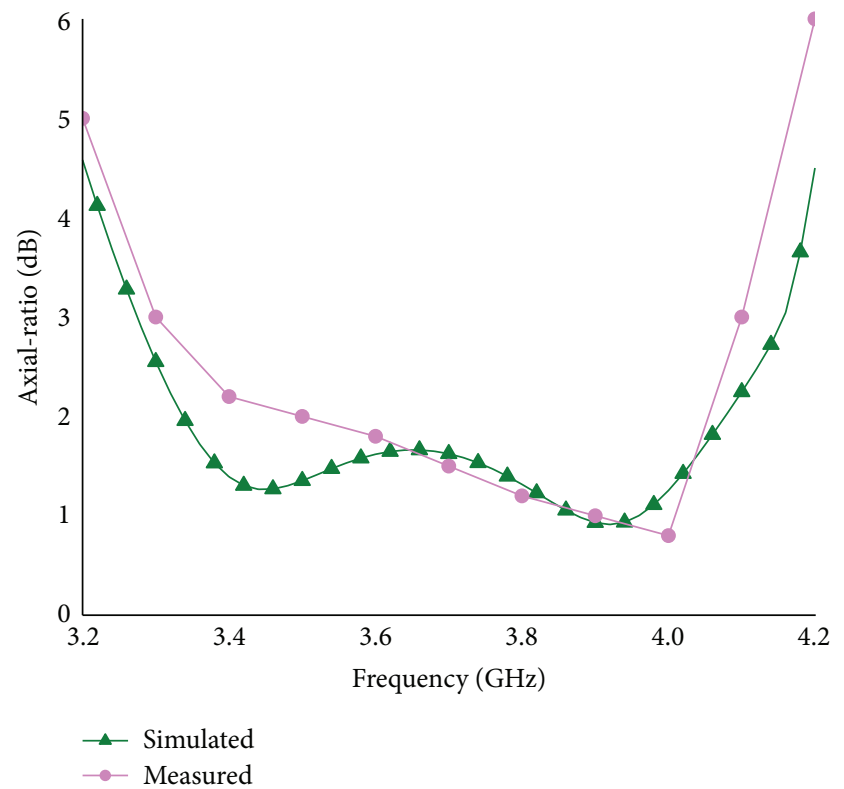

FIgURE 13: Axial-ratio at the zenith versus frequency.

\section{Acknowledgments}

This work was supported by the National Natural Science Foundation (61201058 and 61471240), the Research and Innovation Project of Shanghai Education Commission (12Z112030001), the Scientific Research Foundation for Returned Overseas Chinese Scholars, State Education Ministry, and the Project of SMC Excellent Young Faculty.

\section{References}

[1] S.-K. Lin and Y.-C. Lin, "A compact outer-fed leaky-wave antenna using exponentially tapered slots for broadside circularly polarized radiation," IEEE Transactions on Antennas and Propagation, vol. 60, no. 6, pp. 2654-2661, 2012.

[2] Z. Wang, S. Fang, S. Fu, and S. Jia, "Single-fed broadband circularly polarized stacked patch antenna with horizontally meandered strip for universal UHF RFID applications," IEEE Transactions on Microwave Theory and Techniques, vol. 59, no. 4, pp. 1066-1073, 2011.

[3] C.-W. Su, S.-K. Huang, and C.-H. Lee, "CP microstrip antenna with wide beamwidth for GPS band application," Electronics Letters, vol. 43, no. 20, pp. 1062-1063, 2007.

[4] T.-N. Chang, J.-M. Lin, and Y. G. Chen, "A circularly polarized ring-antenna fed by a serially coupled square slot-ring," IEEE Transactions on Antennas and Propagation, vol. 60, no. 2, pp. 1132-1135, 2012.

[5] T. N. Chang and J. M. Lin, "A novel circularly polarized patch antenna with a serial multislot type of loading," IEEE Transactions on Antennas and Propagation, vol. 55, no. 11, pp. 3345-3347, 2007.

[6] K. H. Lu and T.-N. Chang, "Circularly polarized array antenna with corporate-feed network and series-feed elements," IEEE Transactions on Antennas and Propagation, vol. 53, no. 10, pp. 3288-3292, 2005. 
[7] H. W. Lai, K. M. Mak, and K. F. Chan, "Novel aperture-coupled microstrip-line feed for circularly polarized patch antenna," Progress in Electromagnetics Research, vol. 144, pp. 1-9, 2014.

[8] R. Caso, A. A. Serra, M. Rodriguez-Pino, P. Nepa, and G. Manara, "A wideband slot-coupled stacked-patch array for wireless communications," IEEE Antennas and Wireless Propagation Letters, vol. 9, pp. 986-989, 2010.

[9] A. Buffi, R. Caso, M. R. Pino, P. Nepa, and G. Manara, "Singlefeed circularly polarised aperture-coupled square ring slot microstrip antenna," Electronics Letters, vol. 46, no. 4, pp. 268 $269,2010$.

[10] C. Zhang, X. Liang, X. Bai, J. Geng, and R. Jin, "A broadband dual circularly polarized patch antenna with wide beamwidth," IEEE Antennas and Wireless Propagation Letters, vol. 13, pp. 1457-1460, 2014.

[11] L. Liu, Q. Lu, D. Wu, A. Sambell, and E. Korolkiewicz, "Determination of the transformers turn ratios and design of a circular polarised cross slot coupled antenna," in Proceedings of the 7th International Symposium on Communication Systems, Networks and Digital Signal Processing (CSNDSP '10), pp. 115-118, July 2010.

[12] D. Jaisson, "Transmission line model for the input impedance of a slot-coupled rectangular patch antenna," IEE ProceedingsMicrowaves, Antennas and Propagation, vol. 153, no. 5, pp. 461468, 2006.

[13] T. Chiba, Y. Suzuki, and N. Miyano, "Suppression of higher modes and cross polarized component for microstrip antennas," in Proceedings of the Antennas and Propagation Society International Symposium, vol. 20, pp. 285-288, May 1982. 

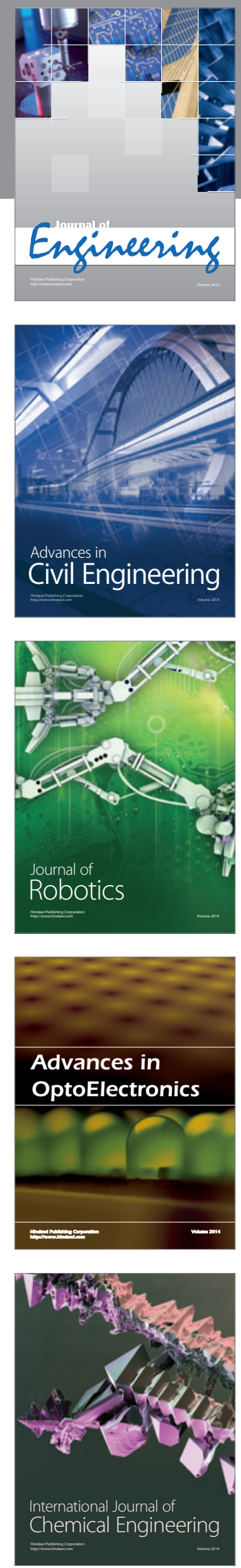

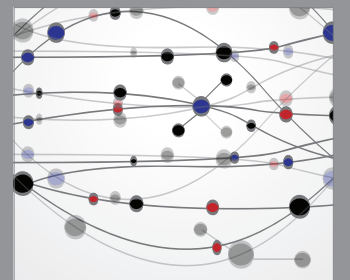

The Scientific World Journal
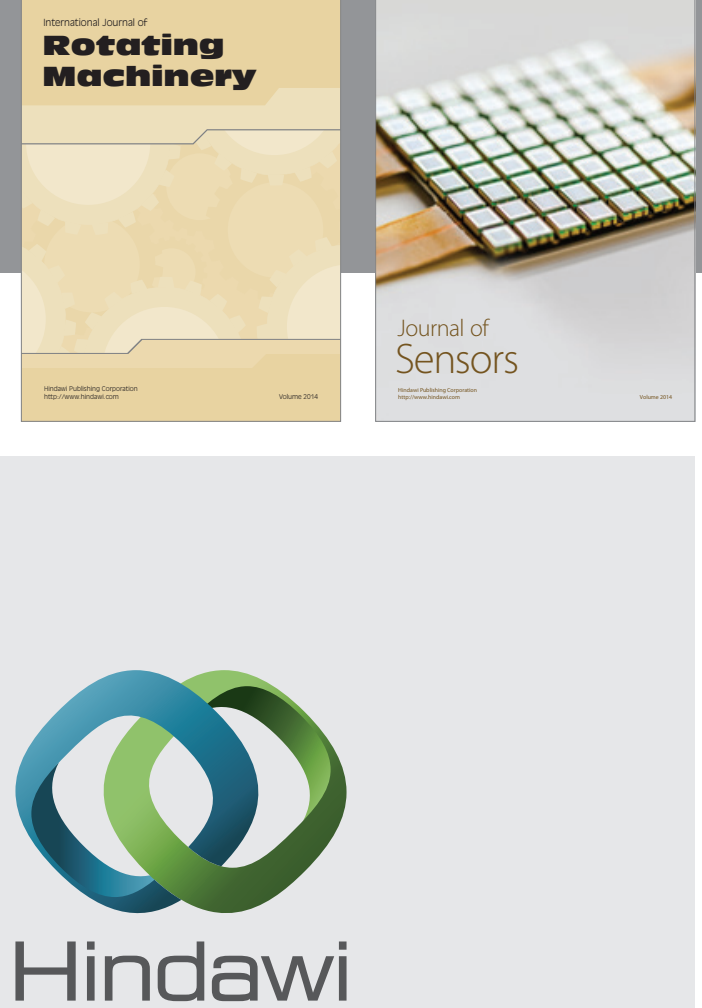

Submit your manuscripts at http://www.hindawi.com
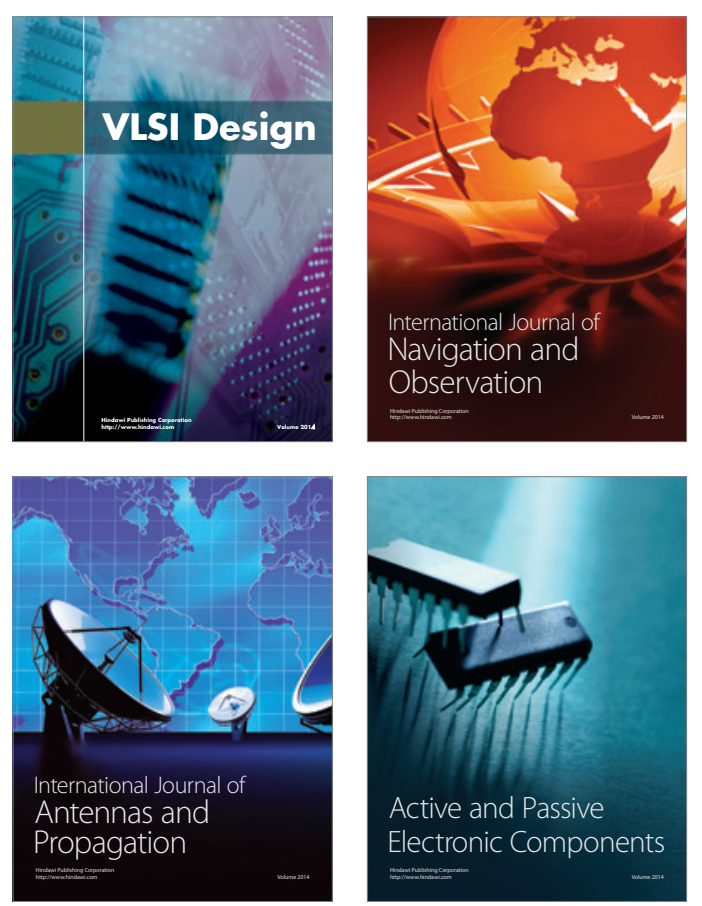
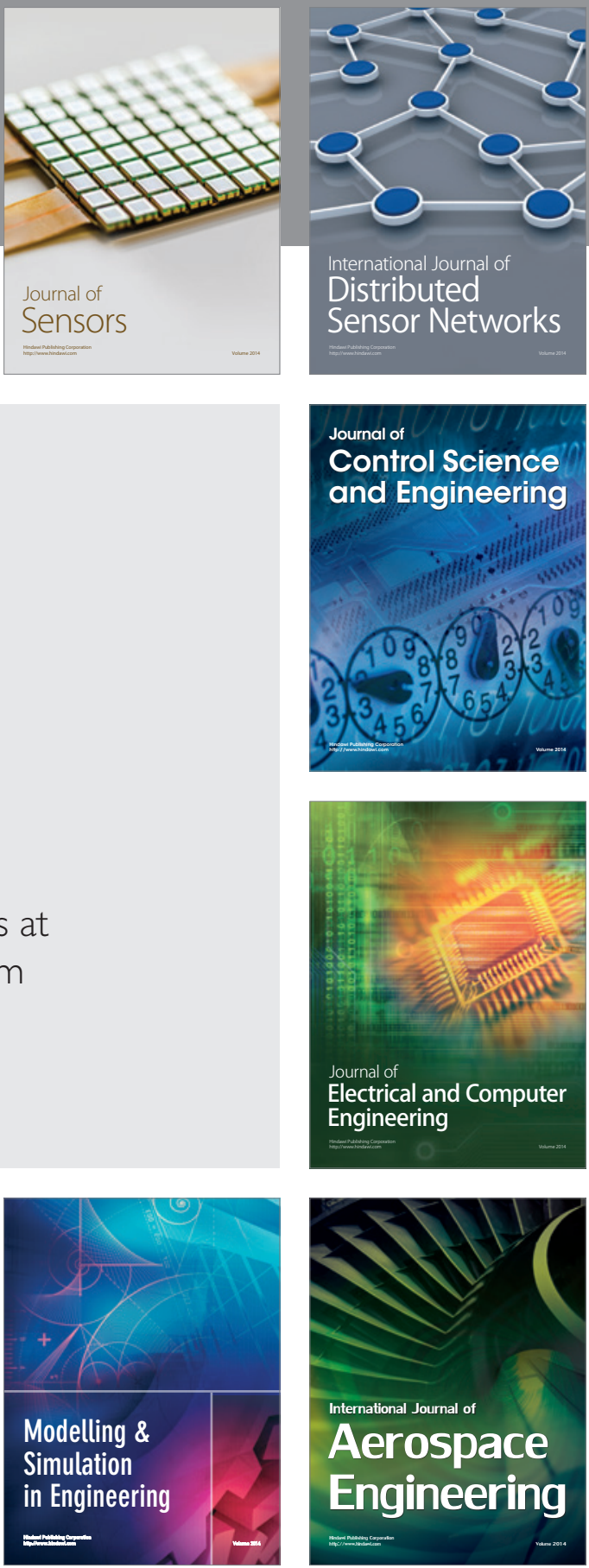

Journal of

Control Science

and Engineering
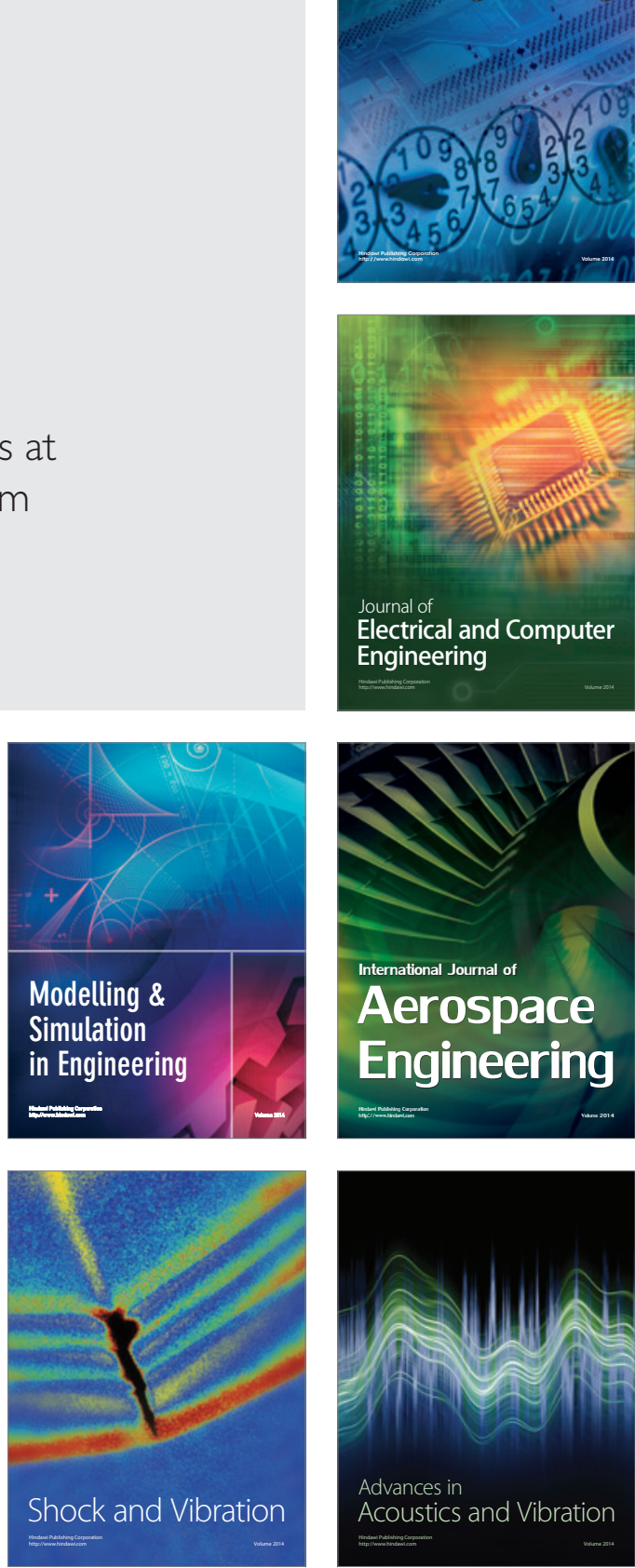